Virginia Commonwealth University VCU Scholars Compass

2011

\title{
Superhalogen properties of CumCln clusters: Theory and experiment
}

Y.J. Ko

Johns Hopkins University

H. Wang

Johns Hopkins University

K. Pradhan

Virginia Commonwealth University, kpradhan@vcu.edu

See next page for additional authors

Follow this and additional works at: http://scholarscompass.vcu.edu/phys_pubs

Part of the Physics Commons

Ko, Y. J., Wang, H., \& Pradhan, K., et al. Superhalogen properties of CumCln clusters: Theory and experiment. The Journal of Chemical Physics, 135, 244312 (2011). Copyright (C) 2011 American Institute of Physics.

\section{Downloaded from}

http://scholarscompass.vcu.edu/phys_pubs/166

This Article is brought to you for free and open access by the Dept. of Physics at VCU Scholars Compass. It has been accepted for inclusion in Physics Publications by an authorized administrator of VCU Scholars Compass. For more information, please contact libcompass@vcu.edu. 
Authors

Y. J. Ko, H. Wang, K. Pradhan, P. Koirala, A. K. Kandalam, K. H. Bowen, and P. Jena 


\title{
Superhalogen properties of $\mathrm{Cu}_{m} \mathrm{Cl}_{n}$ clusters: Theory and experiment
}

\author{
Y. J. Ko, ${ }^{1}$ H. Wang, ${ }^{1}$ K. Pradhan, ${ }^{2}$ P. Koirala, ${ }^{3}$ A. K. Kandalam, ${ }^{3, a)}$ K. H. Bowen, ${ }^{1, a)}$ \\ and P. Jena ${ }^{2, a)}$ \\ ${ }^{1}$ Department of Chemistry and Material Sciences, Johns Hopkins University, Baltimore, Maryland 21218, USA \\ ${ }^{2}$ Department of Physics, Virginia Commonwealth University, Richmond, Virginia 23284, USA \\ ${ }^{3}$ Department of Physics, McNeese State University, Lake Charles, Louisiana 70609, USA
}

(Received 18 August 2011; accepted 30 November 2011; published online 30 December 2011)

\begin{abstract}
Using a combination of density functional theory and anion photoelectron spectroscopy experiment, we have studied the structure and electronic properties of $\mathrm{CuCl}_{n}{ }^{-}(n=1-5)$ and $\mathrm{Cu}_{2} \mathrm{Cl}_{n}{ }^{-}$ ( $n=2-5$ ) clusters. Prominent peaks in the mass spectrum of these clusters occurring at $n=2,3$,

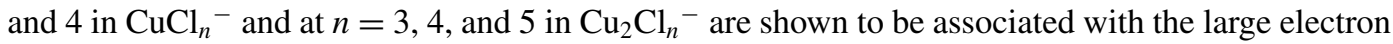
affinities of their neutral clusters that far exceed the value of $\mathrm{Cl}$. While $\mathrm{CuCl}_{n}(n \geq 2)$ clusters are conventional superhalogens with a metal atom at the core surrounded by halogen atoms, $\mathrm{Cu}_{2} \mathrm{Cl}_{n}(n$ $\geq 3$ ) clusters are also superhalogens but with $(\mathrm{CuCl})_{2}$ forming the core. The good agreement between our calculated and measured electron affinities and vertical detachment energies confirm not only the calculated geometries of these superhalogens but also our interpretation of their electronic structure and relative stability. (C) 2011 American Institute of Physics. [doi:10.1063/1.3671457]
\end{abstract}

\section{INTRODUCTION}

Superhalogens are clusters or molecules, which are composed of a central metal atom surrounded by halogen atoms. They form when the number of halogen atoms exceeds the normal valence of the metal atom. Their electron affinities (EAs), which measure the energy gained when an electron is attached to a neutral species, are much larger than that of a halogen atom. Vertical detachment energy (VDE) which measures the energy difference between an anion and its neutral, both at the ground state geometries of the anion, have been found to reach values as high as $14 \mathrm{eV} .{ }^{1}$ Barttlett and co-workers showed that $\mathrm{PtF}_{6}$ molecules can ionize an $\mathrm{O}_{2}$ molecule or $\mathrm{Xe}$ atom ${ }^{2,3}$ and estimated the EA of $\mathrm{PtF}_{6}$ to be $6.8 \mathrm{eV}$. Boldyrev and Gutsev later coined the word superhalogen ${ }^{4-6}$ and outlined conditions a system should satisfy to in order for its EA to be large. Because of the importance of negative ions in chemistry as oxidizing agents, ${ }^{7}$ there is growing interest in the design and synthesis of new superhalogen molecules. Recently, research has also focused on the use of superhalogens as building blocks of energetic materials capable of destroying biologically active materials. ${ }^{8}$ About a decade ago, the smallest superhalogens, $M \mathrm{X}_{2}(M=\mathrm{Li}, \mathrm{Na}$, and $\mathrm{Cu} ; \mathrm{X}=\mathrm{Cl}, \mathrm{Br}$, and $\mathrm{I})$ were studied by photoelectron spectroscopy (PES) and analyzed by $a b$ initio calculations. ${ }^{9,10}$ Later, larger superhalogens $M \mathrm{X}_{3}$ ( $M$ $=\mathrm{Be}, \mathrm{Mg}$, and $\mathrm{Ca} ; \mathrm{X}=\mathrm{Cl}, \mathrm{Br}$, and $\mathrm{F}$ ) (Refs. 11-13) and $M \mathrm{X}_{4}(M=\mathrm{B}$ and $\mathrm{Al} ; \mathrm{X}=\mathrm{F}, \mathrm{Cl}$, and $\mathrm{Br})$ (Refs. 14 and 15$)$ have been studied. Note that the metal atoms are monovalent in $M \mathrm{X}_{2}$, divalent in $M \mathrm{X}_{3}$, and trivalent in $M \mathrm{X}_{4}$. Clusters with more than one metal atom such as $\mathrm{Na}_{x} \mathrm{Cl}_{x+1}(x=1-4)$ (Ref. 16) and $\mathrm{Mg}_{2} \mathrm{~F}_{5}$ (Ref. 17) have also been found to be superhalogens.

\footnotetext{
a) Authors to whom correspondence should be addressed. Electronic addresses: kbowen@jhu.edu; akandalam@mcneese.edu; and pjena@vcu.edu.
}

While most of the prior work on superhalogens has concentrated on $s p$ metal atoms, recent studies have focused on transition and coinage metal atoms as the central core. Examples of the latter class of superhalogens include $\mathrm{MnO}_{4}$ (Ref. 18), $\mathrm{CrO}_{4}$ (Ref. 19), and $\mathrm{ScCl}_{4}$ (Refs. 20 and 21) whose EAs are $5.0 \mathrm{eV}, 4.96 \mathrm{eV}$, and $6.84 \mathrm{eV}$, respectively, while the metal hexafluorides include $\mathrm{AuF}_{6}, \mathrm{PtF}_{6}$, (Refs. 22 and 23) second- and third-row transition metal fluorides, ${ }^{24,25}$ and coinage metal fluorides ${ }^{26}$ have been reported recently. In a recent study, ${ }^{26}$ superhalogens consisting of coinage metal atoms surrounded by $\mathrm{F}$ atoms, $\mathrm{MF}_{n}(M=\mathrm{Cu}, \mathrm{Ag}, \mathrm{Au}, n=1-7)$ was studied systematically. For $n \geq 2$, these clusters possess superhalogen properties and as many as six $\mathrm{F}$ atoms can be bound to a single $\mathrm{Au}$ atom. However, in the case of $\mathrm{Cu}$, the maximum numbers of $\mathrm{F}$ atoms that bind atomically to the $\mathrm{Cu}$ is four. For example in $\mathrm{CuF}_{5}$ cluster, two of the $\mathrm{F}$ atoms dimerize and then weakly bind to the $\mathrm{CuF}_{3}$ portion of the cluster. In the case of anions, the fragmentation energy of $\mathrm{CuF}_{5}{ }^{-}$was found to be four times smaller than that of $\mathrm{CuF}_{4}{ }^{-}$cluster. Unfortunately, there are no experimental data to compare with theory since $\mathrm{F}$ is difficult to handle in experiments. Consequently, we carried out a combined theoretical and experimental study of the $\mathrm{Cu}_{m} \mathrm{Cl}_{n}$ clusters $(m=1,2 ; n=1-5)$.

$\mathrm{Cu}$ usually exists in monovalent (I) and divalent (II) states and hence can easily bind up to two halogen atoms. Since it was shown earlier ${ }^{26}$ that up to four $\mathrm{F}$ atoms can be bound chemically to a neutral $\mathrm{Cu}$ atom and $\mathrm{CuF}_{n}$ clusters $(n$ $\geq 2$ ) are superhalogens, a natural question arises: can a single $\mathrm{Cu}$ atom also bind up to four $\mathrm{Cl}$ atoms and have large EA? Using hybrid density functional theory (DFT) based calculations we studied $\mathrm{CuCl}_{n}$ clusters up to $n=5$. The calculated fragmentation energies of neutral and anionic $\mathrm{CuCl}_{5}$ clusters are very small indeed and suggest that larger $\mathrm{CuCl}_{n}$ clusters $(n$ $\geq 6$ ) will not be energetically very stable. We will show later that this is consistent with the mass spectra of $\mathrm{CuCl}_{n}$ clusters. All $\mathrm{CuCl}_{\mathrm{n}}$ clusters are stable and those with $n \geq 2$ are 
superhalogens. Using our pulsed arc cluster ion source (PACIS) we produced $\mathrm{Cu}$ clusters, which were then allowed to react with $\mathrm{Cl}$. We not only observed $\mathrm{CuCl}_{n}{ }^{-}$species up to $n=6$ but also clusters composed of $\mathrm{Cu}_{2}$ at the core. We have confined our anion PES studies to $\mathrm{CuCl}_{n}$ clusters with $n=1-4$. The calculated EAs and VDEs are compared with the corresponding measured values using anion PES, to verify the ground state geometries of anion and establish the superhalogen properties of these clusters. In Sec. II we provide a brief description of our theoretical and experimental procedure. The results are discussed in Sec. III and summarized in Sec. IV.

\section{THEORETICAL AND EXPERIMENTAL METHODS}

The ground state geometries of neutral and anionic $\mathrm{Cu}_{m} \mathrm{Cl}_{n}$ clusters were obtained by hybrid DFT based electronic structure calculations using GAUSSIAN 03 program. ${ }^{27}$ The hybrid density functional ${ }^{28}$ B3LYP along with 6$311++\mathrm{G}(3 \mathrm{~d})$ basis set was used for all the calculations. Different initial geometries with halogen atoms bound to the $\mathrm{Cu}$ atom(s) both molecularly and chemically were considered for geometry optimization to identify the ground state structures of these clusters. Different possible spin multiplicities were considered for each of the isomers to determine the preferred spin state of these clusters. The convergence for total energy and gradient were set to $10^{-9}$ Hartree and $10^{-4}$ Hartree/Å, respectively. The vibrational frequencies of all the clusters studied are positive and thus the structures are confirmed to belong to minima on the potential energy surface. The zero-point vibrational energy (ZPVE) is not included in the calculations of EAs or fragmentation energies.

Our experimental anion PES study is conducted by crossing a beam of mass-selected negative ions with a fixed frequency photon beam and energy analyzing the resultant photodetached electrons. The photo-detachment process is governed by the energy-conserving relationship, $\mathrm{h} v=\mathrm{EBE}$ $+\mathrm{EKE}$, where $\mathrm{h} v$ is the photon energy, EBE is the electron binding energy, and EKE is the electron kinetic energy. The main information obtained is the electronic energy spectrum of the anion's corresponding neutral at the structure of the anion. Thus, even though these experiments are performed on negative ions, their results pertain to their neutral counterparts as well.

Our apparatus has been described previously. ${ }^{29}$ In brief, the apparatus consists of an ion source, a linear time-of-flight mass selector, a photo-detachment laser, and a magnetic bottle photoelectron spectrometer (MB-PES). The instrumental resolution of the MB-PES is $35 \mathrm{meV}$ at $1 \mathrm{eV}$ EKE. An ArF eximer laser $(193 \mathrm{~nm}, 6.424 \mathrm{eV})$ was used to photodetach the cluster anions of interest. Photoelectron spectra were calibrated against the known atomic lines of $\mathrm{Cu}^{-}$. In this study, $\mathrm{Cu}_{m} \mathrm{Cl}_{n}$ anions were generated with a PACIS that has been described in detail elsewhere. ${ }^{30}$ In brief, a discharge is triggered between two copper rods serving as anode and cathode, vaporizing sample from the cathode. About 2 bar of ultrahigh purity chlorine gas is back-filled into the discharging region. Then, a 30-40 $\mu$ s long $150 \mathrm{~V}$ pulse is applied to the anode causing a discharge between the electrodes in which chlorine gas partially dissociates (generating a momentarily high concentration of $\mathrm{Cl}$ atoms) and copper atoms are vaporized. About 10 bar of helium gas flushes the chlorine-copper plasma mix down a $20 \mathrm{~cm}$ flow tube, where it reacts, cools, and forms clusters. The source was operated at $10 \mathrm{~Hz}$ repetition rate.

\section{RESULTS AND DISCUSSIONS}

\section{A. $\mathrm{CuCl}_{n}(n=1-5)$ clusters: Theory}

We first discuss our results of a single $\mathrm{Cu}$ atom interacting with $\mathrm{Cl}$ atoms to see how the geometries and electronic structures evolve with the addition of each $\mathrm{Cl}$ atom. The ground state geometries of neutral and anionic $\mathrm{CuCl}_{n}$ ( $n=1-5)$ clusters are shown in Figure 1. The geometries of neutral clusters are similar to their corresponding anions for $n=1$ and 2. While the geometries of neutral and anion cluster for $n=3$ are slightly different, they differ considerably for $n=4$. In neutral $\mathrm{CuCl}_{3}$ cluster, we found three iso-energetic, nearly identical isomers that differ in the $\mathrm{Cl}-$ $\mathrm{Cl}$ bond distances (Fig. 1, 3a-3c). The lowest energy structure has $\mathrm{C}_{2 v}$ symmetry, with a weak interaction between two chlorine atoms (Fig. 1, 3a). The bond length between the two chlorine atoms is $2.69 \AA$, which is $32.5 \%$ larger than the $\mathrm{Cl}-$ $\mathrm{Cl}$ bond length $\left(2.03 \AA\right.$ ) in a $\mathrm{Cl}_{2}$ dimer. A highly symmetric $\mathrm{D}_{3 h}$ structure (Fig. 1, 3b) in which there is no $\mathrm{Cl}-\mathrm{Cl}$ interaction is found to be only $0.05 \mathrm{eV}$ higher in energy. The quasimolecular bonding between two $\mathrm{Cl}$ atoms in Fig. 1(3a) suggests that $\mathrm{Cu}$ is in $+\mathrm{II}$ oxidation state while atomic bonding of all $\mathrm{Cl}$ atoms in Fig. 1(3b) suggests that $\mathrm{Cu}$ is in $+\mathrm{III}$ oxidation state. A third isomer $\left(\mathrm{C}_{2 v}\right.$ symmetry) without any interaction

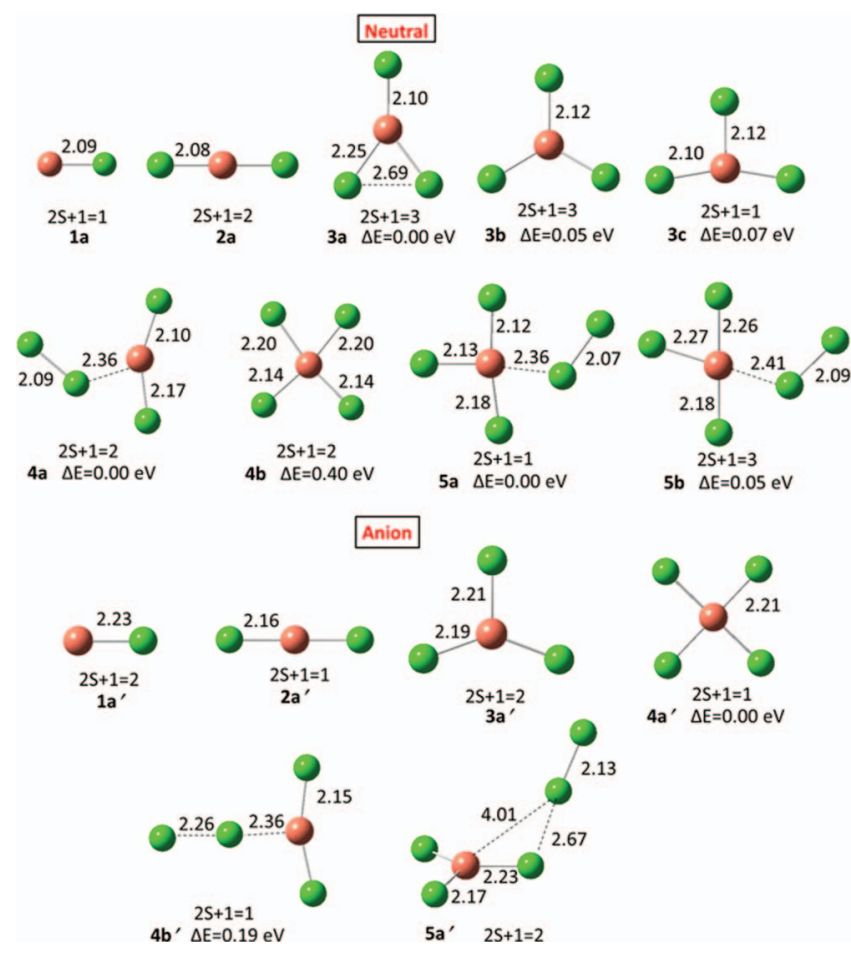

FIG. 1. The lowest energy and few higher energy isomers of neutral and anionic $\mathrm{CuCl}_{n}$ clusters. The green spheres represent chlorine atoms, while the red spheres are copper atoms. All the bond lengths are given in Angstroms. 
between the halogen atoms as in Fig. 1 (3b) but with singlet spin multiplicity is $0.07 \mathrm{eV}$ higher in energy (Fig. 1, 3c). The first two isomers prefer a triplet spin state $(2 \mathrm{~S}+1=3)$. The above small energy differences are within the computational uncertainty $(\sim 0.20 \mathrm{eV})$ of the current level of theory and neutral $\mathrm{CuCl}_{3}$ can exist in either of these spin states. The ground state geometry of $\mathrm{CuCl}_{3}{ }^{-}$cluster has $\mathrm{C}_{2 v}$ symmetry with two distinct $\mathrm{Cu}-\mathrm{Cl}$ bond lengths of 2.21 and $2.19 \AA$ (Fig. 1, 3a') and prefers a doublet spin state.

In neutral $\mathrm{CuCl}_{n}$ clusters with $n \geq 4$, two of the halogen atoms form molecule-like structure while the remaining bind atomically to $\mathrm{Cu}$. For example, in the neutral $\mathrm{CuCl}_{4}$ cluster (Fig. 1, 4a) two of the chlorine atoms form a $\mathrm{Cl}_{2}$ dimer, which in turn binds to the $\mathrm{Cu}$ atom. Thus, one can consider neutral $\mathrm{CuCl}_{4}$ as $\left(\mathrm{CuCl}_{2}\right) \mathrm{Cl}_{2}$ cluster. The fragmentation analysis of the $\mathrm{CuCl}_{n}$ clusters, discussed later, shows $\mathrm{Cl}_{2}$ and $\mathrm{CuCl}_{2}$ as the most preferred fragmentation products of $\mathrm{CuCl}_{4}$ cluster indicating that $\mathrm{CuCl}_{4}$ is indeed a $\left(\mathrm{CuCl}_{2}\right) \mathrm{Cl}_{2}$ complex. In the case of anionic $\mathrm{CuCl}_{4}$ cluster, however, a planar structure (Fig. 1, 4a') with all the four halogen atoms binding atomically to the central $\mathrm{Cu}$ atom ( $\mathrm{D}_{4 h}$ symmetry) is found to be lowest in energy. Another planar isomer, in which a weakly bonded $\mathrm{Cl}_{2}$ interacting with $\mathrm{CuCl}_{2}$ moiety is found to be $0.19 \mathrm{eV}$ higher in energy (Fig. 1, 4b'). Since the energy difference between these two isomers is less than the accuracy of our computational method $(\sim 0.2 \mathrm{eV})$, both these structures are possible for $\mathrm{CuCl}_{4}{ }^{-}$cluster. Interestingly, in the case of neutral $\mathrm{CuCl}_{4}$ cluster, the $\mathrm{D}_{4 h}$ symmetric structure is found to be $0.40 \mathrm{eV}$ higher in energy than the ground state structure containing $\mathrm{Cl}_{2}$ molecule (Fig. 1, 4b). The ground state geometries of $\mathrm{CuCl}_{5}$ and $\mathrm{CuCl}_{5}{ }^{-}$clusters can be viewed as $\left(\mathrm{CuCl}_{3}\right) \mathrm{Cl}_{2}$ and $\left(\mathrm{CuCl}_{3}{ }^{-}\right) \mathrm{Cl}_{2}$ complexes (Fig. 1, 5a and 5a'), respectively. The anionic $\mathrm{CuCl}_{5}$ cluster prefers a doublet $(2 \mathrm{~S}+1=2)$ spin state, while in the case of neutral $\mathrm{CuCl}_{5}$ cluster, both singlet and triplet spin multiplicities are found to be energetically very close, with the singlet lower in energy by $0.05 \mathrm{eV}$. Since $\mathrm{CuCl}_{5}$ exists as $\left(\mathrm{CuCl}_{3}\right) \mathrm{Cl}_{2}$ complex, the spin multiplicity scenario discussed in $\mathrm{CuCl}_{3}$, i.e., singlet and triplet spin states being close in energy, is also reflected in $\mathrm{CuCl}_{5}$ cluster. The average bond lengths of the anionic clusters are larger than the neutral clusters for $n=1$ and 2 while both species have the same average bond length for $n=3,4$, and 5 .

Based on the ground state geometries of neutral and anionic $\mathrm{CuCl}_{n}$ clusters, one can conclude that the maximum oxidation state of $\mathrm{Cu}$ is +3 in these clusters. Interestingly, in our earlier theoretical work on coinage-metal fluoride clusters, it has been shown that $\mathrm{Cu}$ can have a maximum oxidation state of +4 . This difference in the oxidation states of $\mathrm{Cu}$ atom in these two systems (chloride vs. fluorides) can be understood from the fact that fluorine is more electronegative than chlorine and the metal atoms can reach a higher oxidation state when interacting with fluorine. The thermodynamic stability of the neutral and anionic $\mathrm{CuCl}_{n}$ clusters against fragmentation into $\mathrm{CuCl}_{n-1}+\mathrm{Cl}$ and $\mathrm{CuCl}_{n-2}+\mathrm{Cl}_{2}$ units are calculated by the following equations:

$$
\begin{aligned}
\Delta \mathrm{E}_{\text {neutral }} & =-\left[E\left(\mathrm{CuCl}_{n}\right)-E\left(\mathrm{CuCl}_{n-m}\right)-E\left(\mathrm{Cl}_{m}\right)\right], \\
m & =1,2,
\end{aligned}
$$
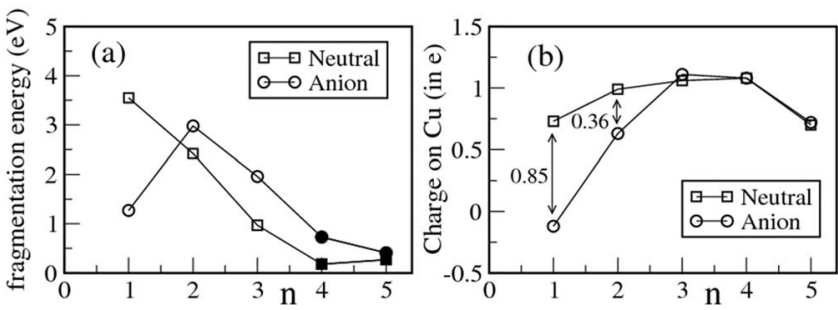

FIG. 2. Calculated (a) fragmentation energies (in eV): filled symbols show that the preferable channel consist of a $\mathrm{Cl}_{2}$ molecule rather than atomic $\mathrm{Cl}$ (see the text for the preferred channels for each cluster) and (b) charge on $\mathrm{Cu}$ atom in $\mathrm{CuCl}_{n}$ clusters.

$$
\begin{aligned}
\Delta \mathrm{E}_{\text {anion }}^{1} & =-\left[E\left(\mathrm{CuCl}_{n}^{-}\right)-E\left(\mathrm{CuCl}_{n-m}^{-}\right)-E\left(\mathrm{Cl}_{m}\right)\right], \\
m & =1,2
\end{aligned}
$$

$$
\begin{aligned}
\Delta \mathrm{E}_{\text {anion }}^{2} & =-\left[E\left(\mathrm{CuCl}_{n}^{-}\right)-E\left(\mathrm{CuCl}_{n-m}\right)-E\left(\mathrm{Cl}_{m}^{-}\right)\right], \\
m & =1,2 .
\end{aligned}
$$

For computation of the fragmentation energies of the anionic clusters, one has to further take into account the possibility that the extra charge can be carried either by $\mathrm{Cl}$ or by the $\mathrm{Cu}-\mathrm{Cl}$ complex. In principle, the preferred fragmentation channel should have the lowest reaction barrier. However, in the absence of such studies, we consider the channel for which $\Delta \mathrm{E}$ is minimum as the preferred channel. The fragmentation energies associated with the minimum energy channel for each cluster are plotted in Figure 2(a). Neutral clusters prefer to dissociate into a $\mathrm{CuCl}_{n-1}$ and $\mathrm{Cl}$ for $n$ $=1-3$. The most preferable fragmentation channel for $\mathrm{CuCl}_{n}$ ( $n=4$ and 5) clusters is $\mathrm{CuCl}_{n-2}+\mathrm{Cl}_{2}$. The corresponding fragmentation energies are calculated to be $0.18 \mathrm{eV}$ and $0.27 \mathrm{eV}$ for $\mathrm{CuCl}_{4}$ and $\mathrm{CuCl}_{5}$, respectively. These small fragmentation energies further reinforces the fact that $\mathrm{CuCl}_{n}$ $\left(n=4\right.$ and 5) clusters exist as $\left(\mathrm{CuCl}_{n-2}\right) \mathrm{Cl}_{2}$ complexes. In the case of anionic $\mathrm{CuCl}_{n}$ clusters, the negative charge resides on the $\mathrm{Cl}$ atom for $n=1$, while in the cases of $\mathrm{CuCl}_{n}{ }^{-}(n \geq 2)$ clusters the extra charge resides on the $\mathrm{CuCl}_{n-1}$ fragment. For $n=2-3$, the most preferred fragmentation channel is found to be $\mathrm{CuCl}_{n-1}{ }^{-}+\mathrm{Cl}$; on the other hand, for $n=4$ and 5, fragmentation leading to $\mathrm{Cl}_{2}$ and $\mathrm{CuCl}_{n-2}{ }^{-}$is the most preferred channel. This transformation of the preferred fragmentation product from $\mathrm{Cl}$ to $\mathrm{Cl}_{2}$ at $n=4$ can be understood from the fact that $\mathrm{CuCl}_{2}{ }^{-}$is the most stable cluster in the anionic series (see Fig. 2(a)) and thus, the $\mathrm{CuCl}_{4}{ }^{-}$prefers to dissociate into $\mathrm{CuCl}_{2}{ }^{-}$cluster and $\mathrm{Cl}_{2}$ but not to $\mathrm{CuCl}_{3}{ }^{-}+\mathrm{Cl}$. The preferred fragmentation path for $\mathrm{CuCl}_{5}{ }^{-}$is consistent with the fact that this cluster forms a $\left(\mathrm{CuCl}_{3}{ }^{-}\right) \mathrm{Cl}_{2}$ complex and thus will fragment into $\mathrm{Cl}_{2}$ and $\mathrm{CuCl}_{3}{ }^{-}$. The fragmentation energy for this channel is calculated to be $0.40 \mathrm{eV}$. Note that a similar transition in the preferred fragmentation channel was observed in $\mathrm{CuF}_{n}$ clusters, ${ }^{31}$ where beyond $n=3$, fragmentation into $\mathrm{CuF}_{n-2}$ and $\mathrm{F}_{2}$ was preferred over other channels.

The calculated VDE values of $\mathrm{CuCl}_{n}{ }^{-}$clusters and EA values of $\mathrm{CuCl}_{n}$ clusters are given in Table I. The EA of $\mathrm{Cl}$ 
TABLE I. Theoretical and experimental EAs of $\mathrm{Cu}_{m} \mathrm{Cl}_{n}(m=1,2 ; n=1-5)$ clusters and VDEs of $\mathrm{Cu}_{m} \mathrm{Cl}_{n}{ }^{-}$( $m=1$ and $\left.2 ; n=1-5\right)$ clusters. All values are given in $\mathrm{eV}$.

\begin{tabular}{lccccc}
\hline \hline & \multicolumn{2}{c}{ Calculated } & & \multicolumn{2}{c}{ Experimental } \\
\cline { 2 - 3 } Cluster $\left(m_{B}\right)$ & EA (eV) & VDE $(e V)$ & & EA (eV) & VDE $(e V)$ \\
\hline $\mathrm{CuCl}$ & 1.44 & 1.54 & & \\
$\mathrm{CuCl}_{2}$ & 4.27 & 4.35 & & $4.3 \pm 0.1$ & $4.6 \pm 0.1$ \\
$\mathrm{CuCl}_{3}$ & 5.27 & 5.65 & & $5.5 \pm 0.1$ & $5.8 \pm 0.05$ \\
$\mathrm{CuCl}_{4}$ & 4.82 & 5.28 & & $4.6 \pm 0.1$ & $5.0 \pm 0.05$ \\
$\mathrm{CuCl}_{5}$ & 5.64 & 5.94 & & \\
$\mathrm{Cu}_{2} \mathrm{Cl}_{2}$ & 1.87 & 2.67 & & \\
$\mathrm{Cu}_{2} \mathrm{Cl}_{3}$ & 4.79 & 4.99 & & $5.0 \pm 0.2$ & $5.2 \pm 0.05$ \\
$\mathrm{Cu}_{2} \mathrm{Cl}_{4}$ & 4.58 & 4.72 & & $4.6 \pm 0.1$ & $4.8 \pm 0.1$ \\
$\mathrm{Cu}_{2} \mathrm{Cl}_{5}$ & 5.15 & 5.99 & & \\
\hline \hline
\end{tabular}

is $3.6 \mathrm{eV}$ and is the highest among all the elements in the periodic table. Apart from $\mathrm{CuCl}$, EA for all other clusters are larger than that of the $\mathrm{Cl}$ atom and hence are classified as superhalogens. To understand the superhalogen properties we have analyzed the total charge on the $\mathrm{Cu}$ and $\mathrm{Cl}$ atoms as a function of $n$ for both neutral and anionic $\mathrm{CuCl}_{n}$ clusters using natural bond orbital (NBO) analysis. ${ }^{31}$ The results are plotted in Fig. 2(b). In all neutral $\mathrm{CuCl}_{n}$ clusters, the total charge on $\mathrm{Cu}$ atoms is positive indicating that charge is transferred from $\mathrm{Cu}$ to the $\mathrm{Cl}$ atoms. In anionic clusters, the extra electron either goes to compensate the positive charge on the $\mathrm{Cu}$ atom or is distributed over the $\mathrm{Cl}$ atoms. In the case of $\mathrm{CuCl}^{-}$, majority of the electron's charge goes to positively charged $\mathrm{Cu}$ and thus results in a low EA. On the other hand, in the case of the $\mathrm{CuCl}_{2}{ }^{-}$a large part (74\%) of the extra electron's charge is distributed over two $\mathrm{Cl}$ atoms. This results in a large EA for $\mathrm{CuCl}_{2}$ and makes it a superhalogen. In larger $\mathrm{CuCl}_{n}$ clusters, addition of an extra electron does not change the charge on the $\mathrm{Cu}$, implying that the electron's charge is again distributed among all the halogen atoms, rather than the positively charged metal center. The delocalization of the electron's charge over the halogen atoms results in the superhalogen behavior of $\mathrm{CuCl}_{n}(n \geq 2)$ clusters. The calculated VDE and EA values (see Table I) are close to each other for $n=1$ and 2 due to the similarity in their ground state geometries while the difference is significant for $n=3,4$, and 5 .

Since the lowest energy structures of neutral and negatively charged $\mathrm{CuCl}_{4}$ cluster are different and there exist two isomers in anion that are close in energy $(\Delta \mathrm{E}=0.19 \mathrm{eV})$, in addition to the EA, we have calculated the adiabatic detachment energy (ADE) and VDE for both the anionic isomers. The ADE value was obtained by calculating the energy difference between the ground state geometry of the anionic cluster and the structurally similar isomer of its neutral counterpart. In cases where the ground state geometries of neutral and anionic clusters are similar, the ADE of the anionic cluster is equal to the EA of the corresponding neutral cluster. In the case of $\mathrm{CuCl}_{4}{ }^{-}$, the calculated ADE for the lowest energy isomer (Fig. 1, 4a') corresponds to $5.22 \mathrm{eV}$, while the $\mathrm{ADE}$ for the higher energy isomer (Fig. 1, $4 \mathrm{~b}^{\prime}$ ) is calculated to be $4.64 \mathrm{eV}$. The corresponding VDEs of these two isomers are 5.29 and $5.36 \mathrm{eV}$, respectively. The EA, the energy differ- ence between the lowest energy anion and neutral isomers, of $\mathrm{CuCl}_{4}$ cluster is $4.82 \mathrm{eV}$. On comparing our calculated values with that of the measured values (see Table I), we conclude that both the isomers (Fig. 1, $4 \mathrm{a}^{\prime}$ and $4 \mathrm{~b}^{\prime}$ ) are contributing towards the PES spectrum.

The superhalogen property of $\mathrm{CuCl}_{2}$ and $\mathrm{CuCl}_{3}$ is consistent with the oxidation state of +1 and +2 of the $\mathrm{Cu}$ atom. $\mathrm{Cu}$ also has been $\mathrm{known}^{32}$ to have an oxidation state of +3 and hence $\mathrm{CuCl}_{4}$ is also a superhalogen. But large EA of $\mathrm{CuCl}_{5}$ cannot be directly connected to the oxidation state of $\mathrm{Cu}$. Since $\mathrm{CuCl}_{5}$ cluster exists as $\left(\mathrm{CuCl}_{3}\right) \mathrm{Cl}_{2}$ complex, the large EA $(5.64 \mathrm{eV})$ of this cluster is actually a reflection of the EA of $\mathrm{CuCl}_{3}(5.27 \mathrm{eV})$ moiety. In $\mathrm{CuCl}_{5}$, the oxidation state of $\mathrm{Cu}$ is +3 but not +5 . Note that a similar scenario was observed in our previously reported work ${ }^{26}$ on $\mathrm{CuF}_{n}$ clusters. Thus, studying the reaction of a metal atom with halogen atoms and measuring their EAs allow a unique way to characterize the oxidation state of metals.

\section{CuCIn $(n=2-4)$ clusters: Experiment}

To verify our theoretical prediction, we have carried out experimental studies of $\mathrm{Cu}$ clusters interacting with chlorine. In Fig. 3 we show the mass spectrum of $\mathrm{Cu}_{m} \mathrm{Cl}_{n}{ }^{-}$clusters. In the $\mathrm{CuCl}_{n}{ }^{-}$series $(n=2-6)$, we see that the peaks of $\mathrm{CuCl}_{2}{ }^{-}$ and $\mathrm{CuCl}_{3}{ }^{-}$are more intense than any other peaks. While both kinetic and thermodynamic effects play important roles in the intensity distribution in the mass spectrum, conspicuous peaks in mass spectra of $\mathrm{Na}$ and other clusters have been successively interpreted ${ }^{33}$ on the basis of their relative stability. For example, clusters with even number of electrons tend to be more stable than those with odd number of electrons due to shell closing. In a PACIS source, clusters are usually produced as charged species. In this sense, $\mathrm{CuCl}_{n}{ }^{-}$clusters with even number of $\mathrm{Cl}$ atoms should be more stable than those with clusters containing odd number of $\mathrm{Cl}$ atoms, if the clusters

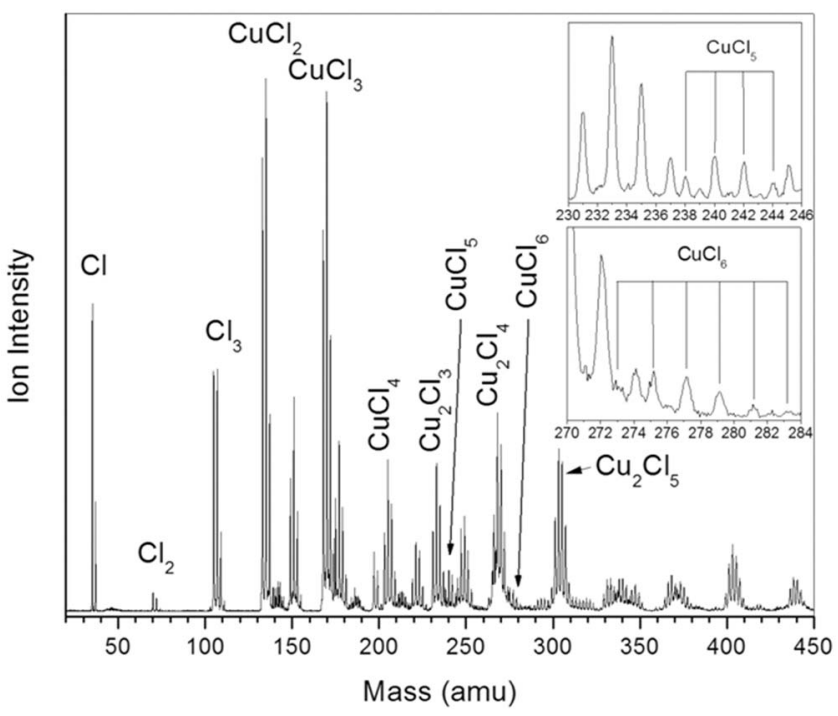

FIG. 3. Typical mass spectrum of $\mathrm{Cu}_{m} \mathrm{Cl}_{n}{ }^{-}$clusters generated in PACIS. The insets show selected magnified portions of the mass spectrum, revealing the expected isotope patterns. 
are born as anions. Reverse is the case if they are born neutral. However, the peak intensities of both $\mathrm{CuCl}_{2}{ }^{-}$and $\mathrm{CuCl}_{3}{ }^{-}$are about the same. We will show in the following that the enhanced stabilities of these anion clusters are due to the superhalogen properties of their neutral counterparts, which allow them to bind an electron with energies much larger than that of the EA of the $\mathrm{Cl}$ atom. The small intensity of the $\mathrm{CuCl}_{5}{ }^{-}$ peak is consistent with our calculated ground state geometry of this cluster and its small fragmentation energy.

To demonstrate the role of superhalogen character of neutral clusters in the stability of their anionic counterparts, we have measured the EA of $\mathrm{CuCl}_{n}$ clusters and VDE of their corresponding anionic clusters by anion PES. The former is the energy difference between the ground state of the anion and corresponding neutral while the VDE is the energy difference between the ground state of the anion and it's neutral at the anion ground state energy. When these geometries remain fairly unchanged after the removal of the extra electron, the photoelectron spectrum remains sharp and EA and VDE are very close to each other.

In Figure 4, we show the photoelectron spectra of $\mathrm{CuCl}_{n}{ }^{-}$ $(n=2-4)$ clusters. The measured EA and VDE are compared with our calculated results in Table I. Note that the agreement is very good and validates not only the theoretical procedure but also the structure of the clusters. Most interesting in these data is of course the large $\mathrm{EAs}$ of $\mathrm{CuCl}_{n}(n=2-4)$ clusters.

The prominent peaks in the mass spectrum in Fig. 3 of these clusters can be partly attributed to their thermodynamic stability. Note that the peak intensity of $\mathrm{CuCl}_{2}{ }^{-}$is larger than that of $\mathrm{CuCl}_{4}{ }^{-}$. This is consistent with the result that the energy gain in adding a $\mathrm{Cl}$ to $\mathrm{CuCl}^{-}$cluster is $2.98 \mathrm{eV}$ while that in going from $\mathrm{CuCl}_{3}{ }^{-}$to $\mathrm{CuCl}_{4}{ }^{-}$is only $1.06 \mathrm{eV}$. In addition, the near identical EA values of $\mathrm{CuCl}_{2}$ and $\mathrm{CuCl}_{4}$ clusters can be due to the fact that the neutral $\mathrm{CuCl}_{2}$ cluster is in fact a

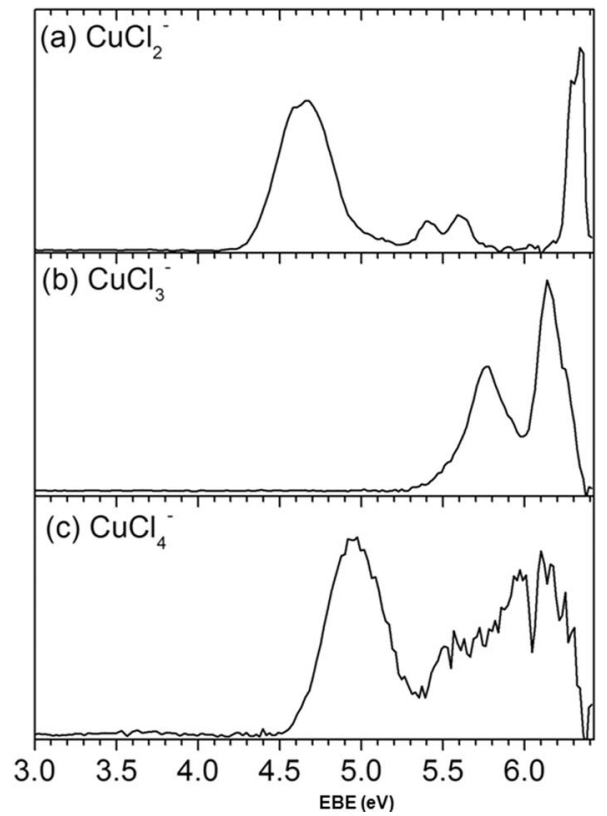

FIG. 4. Photoelectron spectra of $\mathrm{CuCl}_{n}{ }^{-}(n=2-4)$ cluster anions recorded with $193 \mathrm{~nm}$ photons.
$\left(\mathrm{CuCl}_{2}\right) \mathrm{Cl}_{2}$ complex and the $\mathrm{CuCl}_{2}$ unit of this complex is contributing towards the PES spectrum of the $\mathrm{CuCl}_{4}$.

\section{Comparison of $\mathrm{CuCl}_{n}$ with $\mathrm{CuF}_{n}$}

Recently, a systematic theoretical study ${ }^{26}$ of the EAs of $\mathrm{CuF}_{n}$ clusters was reported. Although no experimental studies on this system have been carried out, it is interesting to compare the structure and EAs of the two systems as both $\mathrm{F}$ and $\mathrm{Cl}$ are halogen atoms. We note that in $\mathrm{CuF}_{n}{ }^{-}$or $\mathrm{CuCl}_{n}{ }^{-}$clusters up to four $\mathrm{F}$ or $\mathrm{Cl}$ atoms can be bound directly to the $\mathrm{Cu}$ atom. In $\mathrm{CuF}_{5}{ }^{-}$cluster, four of the $\mathrm{F}$ atoms can be bound to $\mathrm{Cu}$ atom directly while only three of $\mathrm{Cl}$ atoms are bound to $\mathrm{Cu}$ atom in $\mathrm{CuCl}_{5}{ }^{-}$cluster. The main reason for this differing behavior is that the binding energy of $\mathrm{Cl}_{2}$ molecule, namely $2.28 \mathrm{eV}$, is larger than the binding energy of $\mathrm{F}_{2}$, namely, $1.52 \mathrm{eV}$. The equilibrium geometries of $\mathrm{CuF}_{n}$ and $\mathrm{CuCl}_{n}$ clusters are also different. In neutral $\mathrm{CuF}_{n}$ clusters, $\mathrm{F}$ atoms are atomically bound to $\mathrm{Cu}$ for $n \leq 4$ while two of the $\mathrm{F}$ atoms are bound molecularly in $\mathrm{CuF}_{5}$. In contrast, in $\mathrm{CuCl}_{n}$ clusters up to only three $\mathrm{Cl}$ atoms are bound atomically to the $\mathrm{Cu}$. The fourth $\mathrm{Cl}$ atom in neutral $\mathrm{CuCl}_{4}$ is interacting with one of the $\mathrm{Cl}$ atoms rather than the $\mathrm{Cu}$ atom. Geometry of $\mathrm{CuCl}_{5}$ is similar to the $\mathrm{CuF}_{5}$ cluster. We also note that the EAs of $\mathrm{CuF}_{n}$ are 1.59, $3.79,5.86,6.91$, and 6.87 for $n=1,2,3,4$, and 5, respectively. These are larger than those shown in Table I for the corresponding $\mathrm{CuCl}_{n}$ system.

\section{B. $\mathrm{Cu}_{2} \mathrm{Cl}_{n}(n=2-5)$ clusters}

In addition to the $\mathrm{CuCl}_{n}$ peaks in the mass spectrum in Fig. 3, we also see peaks for $\mathrm{Cu}_{2} \mathrm{Cl}_{3}{ }^{-}$and $\mathrm{Cu}_{2} \mathrm{Cl}_{4}{ }^{-}$clusters. To understand the stability of these clusters we have measured the photoelectron spectra which are shown in Figure 5. We note that the ADE and VDE of these clusters are also large and they too belong to the superhalogen series. However, unlike the conventional superhalogens discussed above that have only one metal atom at the core, the above superhalogens have two $\mathrm{Cu}$ atoms. It is relevant to mention that similar superhalogens consisting of multiple metal atoms have been

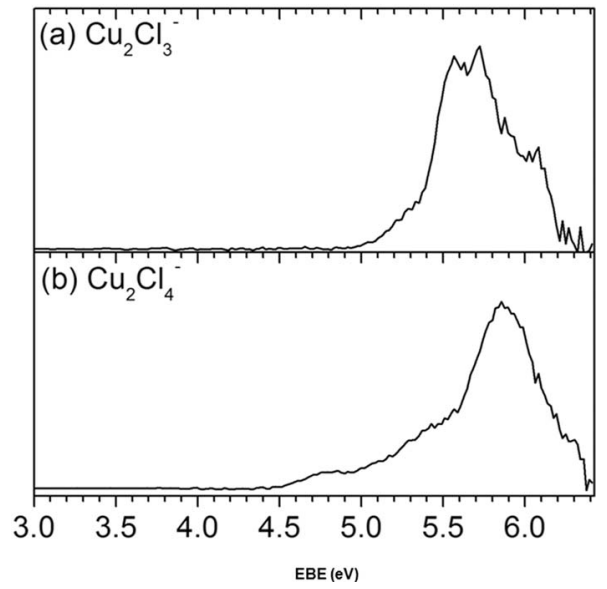

FIG. 5. Photoelectron spectra of $\mathrm{Cu}_{2} \mathrm{Cl}_{n}{ }^{-}(n=3$ and 4) cluster anions recorded with $193 \mathrm{~nm}$ photons. 

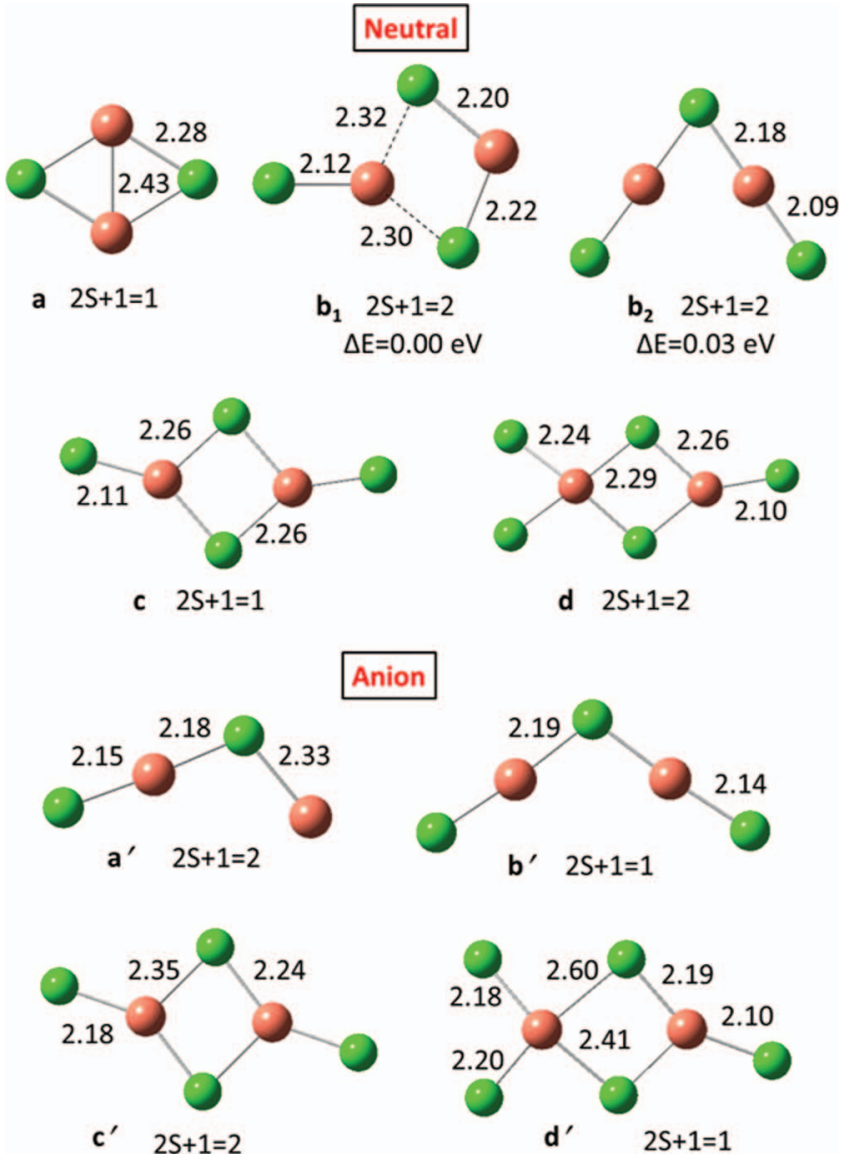

FIG. 6. Optimized geometries of neutral and anionic $\mathrm{Cu}_{2} \mathrm{Cl}_{n}(n=2-5)$ clusters. The green spheres represent chlorine atoms, while the red spheres are copper atoms. All the bond lengths are given in Angstroms.

observed earlier in $\mathrm{Na}_{m} \mathrm{Cl}_{n}$ (Ref. 16), $\mathrm{Au}_{m}\left(\mathrm{BO}_{2}\right)_{n}$ (Ref. 34), and very recently in $\mathrm{Mn}_{x} \mathrm{Cl}_{y}$ (Ref. 35) clusters and predicted theoretically. ${ }^{17,36-38}$ To understand the origin of the superhalogen behavior of these multi-metal clusters, we note that $\mathrm{Cu}_{m} \mathrm{Cl}_{m+1}$ can be written as $(\mathrm{CuCl})_{m} \mathrm{Cl}$. Here, $\mathrm{Cu}$ exists in the oxidation state of +1 . Thus, $\mathrm{Cu}_{m} \mathrm{Cl}_{m+1}$ clusters behave as a superhalogen, but the core is replaced by $\mathrm{CuCl}$ instead of just the $\mathrm{Cu}$ atom. $\mathrm{Cu}$ has an oxidation state of +1 in $\mathrm{Cu}_{2} \mathrm{Cl}_{3}$ cluster which can be written as $(\mathrm{CuCl})_{2} \mathrm{Cl}$. If $\mathrm{Cu}$ were to have an oxidation state of +2 in $\mathrm{Cu}_{m} \mathrm{Cl}_{n}$ clusters, $\left(\mathrm{CuCl}_{2}\right)_{2} \mathrm{Cl}$ should behave as a superhalogen and hence should be stable. Note that a similar behavior has been observed in $\mathrm{Mn}_{2} \mathrm{Cl}_{5}$ (Ref. 30) and theoretically predicted for $\mathrm{Mg}_{2} \mathrm{~F}_{5}$ (Ref. 12) cluster. There is a significant peak for $\mathrm{Cu}_{2} \mathrm{Cl}_{5}{ }^{-}$which confirms the possibility of +2 oxidation state of $\mathrm{Cu}$.

The ground state and higher energy geometries of neutral and negatively charged $\mathrm{Cu}_{2} \mathrm{Cl}_{n}(n=2-5)$ clusters are given in Figure 6. The ground state geometries of neutral and anionic $\mathrm{Cu}_{2} \mathrm{Cl}_{2}$ cluster are different. The neutral $\mathrm{Cu}_{2} \mathrm{Cl}_{2}$ cluster forms a rhombus structure $\left(\mathrm{C}_{2 v}\right.$ symmetry) with $\mathrm{Cu}-\mathrm{Cl}$ bond lengths of $2.28 \AA$ and $\mathrm{Cu}-\mathrm{Cu}$ bond length $2.43 \AA$ (Fig. 6, a). The ground state geometry of $\mathrm{Cu}_{2} \mathrm{Cl}_{2}{ }^{-}$cluster, on the other hand, is a bent open structure with $\mathrm{C}_{\mathrm{s}}$ symmetry (Fig. 6, $\mathrm{a}^{\prime}$ ). In this geometry, there are no metal-metal bonds and can be derived from the $\mathrm{CuCl}_{2}$ cluster (Fig. 1, 2a) with the second $\mathrm{Cu}$ atom binding to one of the halogen atoms. Interestingly, the rhombus structure, which is the ground state in neutral, is $0.89 \mathrm{eV}$ higher in energy than the bent structure. The change in the ground state geometry from a rhombus structure in neutral to a bent structure in anion can be understood from the MO analysis. The LUMO of the neutral $\mathrm{Cu}_{2} \mathrm{Cl}_{2}$ cluster is twofold degenerate, the addition of an electron to LUMO results in distortion of the structure (breaking of $\mathrm{Cu}-\mathrm{Cu}$ and $\mathrm{Cu}-\mathrm{Cl}$ bonds); thereby lifting the symmetry.

We now turn to neutral and anionic $\mathrm{Cu}_{2} \mathrm{Cl}_{3}$ cluster. The lowest energy geometry (Cs symmetry) of neutral $\mathrm{Cu}_{2} \mathrm{Cl}_{3}$ cluster can be seen as an extension of neutral $\mathrm{Cu}_{2} \mathrm{Cl}_{2}$ cluster, where the third $\mathrm{Cl}$ atom binds to one of the $\mathrm{Cu}$ atoms of the rhombus (Fig. 6, $b_{1}$ ). The addition of this halogen atom caused the breaking of $\mathrm{Cu}-\mathrm{Cu}$ bond and weakening the two existing $\mathrm{Cu}-\mathrm{Cl}$ bonds ( $10 \%$ elongation); thereby resulting in a threefold coordination for one of the metal atoms. Another planar isomer $\left(\mathrm{C}_{2 v}\right.$ symmetry) in which both the $\mathrm{Cu}$ atoms are twofold coordinated is found to be $0.03 \mathrm{eV}$ higher in energy (Fig. 6, $b_{2}$ ). Most importantly, this isomer can be derived from the ground state geometry of $\mathrm{Cu}_{2} \mathrm{Cl}_{2}{ }^{-}$cluster. Interestingly, the structural configuration corresponding to the lowest energy geometry of neutral $\mathrm{Cu}_{2} \mathrm{Cl}_{3}$ cluster is not even a minimum on the potential energy surface of the $\mathrm{Cu}_{2} \mathrm{Cl}_{3}{ }^{-}$cluster. The ground state geometry (Fig. 6, b') of $\mathrm{Cu}_{2} \mathrm{Cl}_{3}{ }^{-}$corresponds to a bent structure $\left(\mathrm{C}_{2 v}\right.$ symmetry), similar to that of the higher energy isomer of neutral $\mathrm{Cu}_{2} \mathrm{Cl}_{3}$. A comparison of the NBO charge distributions in the ground state $\mathrm{Cu}_{2} \mathrm{Cl}_{3}{ }^{-}$ cluster (Fig. 6, b') and the structurally similar $\mathrm{Cu}_{2} \mathrm{Cl}_{3}$ (Fig. 6, $\mathrm{b}_{2}$ ) shows that the extra-electron in the anionic cluster is delocalized over the entire cluster, with $40 \%$ distributed over the metal atoms, while the rest $60 \%$ over the halogen atoms. Thus, the delocalization of the electron on the entire cluster, as opposed to the positively charged $\mathrm{Cu}$ atoms results in the superhalogen behavior of $\mathrm{Cu}_{2} \mathrm{Cl}_{3}$ cluster, which is discussed in detail below. The ground state geometries of neutral and negatively charged $\mathrm{Cu}_{2} \mathrm{Cl}_{4}$ cluster (Fig. 6, c and $\mathrm{c}^{\prime}$ ) can be derived from the lowest energy isomer of $\mathrm{Cu}_{2} \mathrm{Cl}_{3}$ (Fig. 6, $\mathrm{b}_{1}$ ), where the fourth chlorine binds to the low coordinated $\mathrm{Cu}$ atom. $\mathrm{Cu}_{2} \mathrm{Cl}_{5}$ cluster can be considered as an extension of $\mathrm{Cu}_{2} \mathrm{Cl}_{4}$, where the fifth chlorine atom binds to one of the $\mathrm{Cu}$ atoms, making it fourfold coordinated, while the other $\mathrm{Cu}$ atom has a threefold coordination. The neutral and anionic $\mathrm{Cu}_{2} \mathrm{Cl}_{5}$ clusters are similar to each other (Fig. 6, $\mathrm{d}_{\text {and }} \mathrm{d}^{\prime}$ ).

To understand the stability of the $\mathrm{Cu}_{2} \mathrm{Cl}_{n}{ }^{-}(n=2-5)$ clusters, we have calculated the fragmentation energies of these clusters via different fragmentation channels. Our calculations show that the most preferred channel has $\mathrm{CuCl}_{2}{ }^{-}$clusters as the end product. This is because of the high stability of $\mathrm{CuCl}_{2}{ }^{-}$cluster. In Fig. 7, we show the fragmentation channels with the required energies for fragmentation. The energy required to dissociate $\mathrm{Cu}_{2} \mathrm{Cl}_{2}{ }^{-}$cluster is much less than that of $\mathrm{Cu}_{2} \mathrm{Cl}_{3}{ }^{-}$or $\mathrm{Cu}_{2} \mathrm{Cl}_{4}{ }^{-}$or $\mathrm{Cu}_{2} \mathrm{Cl}_{5}{ }^{-}$cluster. This further explains the observed peaks of $\mathrm{Cu}_{2} \mathrm{Cl}_{3}{ }^{-}$and $\mathrm{Cu}_{2} \mathrm{Cl}_{4}{ }^{-}$clusters in the mass spectra along with $\mathrm{Cu}_{2} \mathrm{Cl}_{5}{ }^{-}$cluster as shown in Fig. 3.

The calculated EA values of $\mathrm{Cu}_{2} \mathrm{Cl}_{n}$ and $\mathrm{VDE}$ values of $\mathrm{Cu}_{2} \mathrm{Cl}_{n}{ }^{-}(n=2-5)$ clusters are given in Table I. The EA of $\mathrm{Cu}_{2} \mathrm{Cl}_{2}$ is expected to be small. This is because two $\mathrm{Cu}$ atoms donate two electrons to complete the $p$-shell of the 


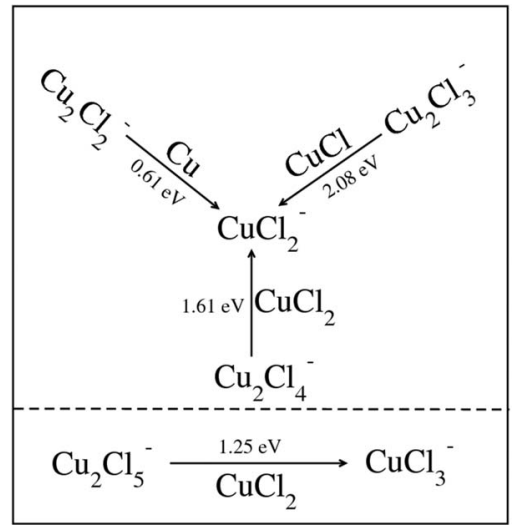

FIG. 7. Fragmentation channels for $\mathrm{Cu}_{2} \mathrm{Cl}_{n}{ }^{-}(n=2-5)$ clusters are shown to describe the preferred product.

$\mathrm{Cl}$ atoms; hence, the added electron goes to neutralize the positive charge on the $\mathrm{Cu}$ atom as opposed to being distributed among the $\mathrm{Cl}$ atoms. However, as more $\mathrm{Cl}$ atoms are added to $\mathrm{Cu}_{2}$, the extra electron redistributes itself among the $\mathrm{Cl}$ atoms and hence they behave as superhalogens. The computed results agree well with experiment. We also note that the EA of $\mathrm{CuCl}_{3}$ is larger than that of $\mathrm{Cu}_{2} \mathrm{Cl}_{3}$ or $\mathrm{Cu}_{2} \mathrm{Cl}_{4}$ clusters. Average charges on $\mathrm{Cu}$ atoms indicate that only $0.38 e$ and $0.24 e$ of the extra electron goes to $\mathrm{Cu}$ atoms in $\mathrm{Cu}_{2} \mathrm{Cl}_{3}{ }^{-}$and $\mathrm{Cu}_{2} \mathrm{Cl}_{4}{ }^{-}$clusters, respectively, while $0.64 e$ of the extra electron goes to the $\mathrm{Cu}$ atoms in $\mathrm{Cu}_{2} \mathrm{Cl}_{2}{ }^{-}$cluster. Difference between the average charge on $\mathrm{Cu}$ atoms in both neutral and anion $\mathrm{Cu}_{2} \mathrm{Cl}_{5}$ clusters are only $0.06 e$ of the electronic charge and explain the larger EA.

\section{CONCLUSIONS}

In summary, a synergistic study involving density functional theory and PES of the structure and electronic properties of $\mathrm{Cu}_{m} \mathrm{Cl}_{n}$ clusters has yielded many interesting results: (1) $\mathrm{CuCl}_{n}$ clusters with $n \geq 2$ are superhalogens with EAs substantially higher than that of $\mathrm{Cl}$, (2) $\mathrm{Cu}_{2} \mathrm{Cl}_{3}$ and $\mathrm{Cu}_{2} \mathrm{Cl}_{4}$ also show superhalogen properties where the core is a $(\mathrm{CuCl})_{2}$ cluster; thus, these superhalogens are different from the conventional superhalogens, (3) the clusters studied show that the oxidation state of $\mathrm{Cu}$ can be as high as III, (4) the pronounced peaks observed in the mass spectrum are attributed to the superhalogen property of the clusters, (5) clusters of $\mathrm{CuCl}_{n}$ do exhibit properties that are different from those of $\mathrm{CuF}_{n}$, and (6) once suitable cations are identified, new salts can be synthesized with strong oxidizing properties.

\section{ACKNOWLEDGMENTS}

The experimental work (K.H.B.) was conducted with support by The Defense Threat Reduction Agency. The computational work is supported in part by grants from the
Defense Threat Reduction Agency and U.S. Department of Energy. P.K. acknowledges financial support from Honors College, McNeese State University.

${ }^{1}$ S. Freza and P. Skurski, Chem. Phys. Lett. 487, 19 (2010).

${ }^{2}$ N. Barttlett, Proc. Chem. Soc., London 218 (1962).

${ }^{3}$ N. Barttlett and D. H. Lohmann, Proc. Chem. Soc., London 115 (1962).

${ }^{4}$ G. L. Gutsev and A. I. Boldyrev, Chem. Phys. 56, 277 (1981).

${ }^{5}$ G. L. Gutsev and A. I. Boldyrev, Chem. Phys. Lett. 101, 441 (1983).

${ }^{6}$ G. L. Gutsev and A. I. Boldyrev, Adv. Chem. Phys. 61, 169 (1985).

${ }^{7}$ D. F. Hunt, G. C. Stafford, Jr., F. W. Crow, and J. W. Russell, Anal. Chem. 48, 2098 (1976).

${ }^{8}$ Q. Wang, Q. Sun, and P. Jena, J. Chem. Phys. 131, 124301 (2009).

${ }^{9}$ X.-B. Wang, C.-F. Ding, L.-S. Wang, A. Boldyrev, and J. Simons, J. Chem. Phys. 110, 4763 (1999).

${ }^{10}$ X. B. Wang, L. S. Wang, R. Brown, P. Schwerdtfeger, D. Schroder, and H. Schwarz, J. Chem. Phys. 114, 7388 (2001).

${ }^{11}$ M. Elliot, E. Koyle, A. I. Boldyrev, X.-B. Wang, and L.-S. Wang, J. Phys. Chem. A 109, 11560 (2005).

${ }^{12}$ I. Anusiewicz and P. Skurski, Chem. Phys. Lett. 358, 426 (2002).

${ }^{13}$ I. Anusiewicz, M. Sobczyk, I. Dabkowska, and P. Skurski, Chem. Phys. 291, 171 (2003).

${ }^{14}$ C. Sikorska, S. Smuczynska, P. Skurski, and I. Anusiewicz, Inorg. Chem. 47, 7348 (2008).

${ }^{15}$ G. L. Gutsev, P. Jena, and R. J. Bartlett, Chem. Phys. Lett. 292, 289 (1998).

${ }^{16}$ A. N. Alexandrova, A. I. Boldyrev, Y.-J. Fu, X. Yang, X.-B. Wang, and L.-S. Wang, J. Chem. Phys. 121, 5709 (2004).

${ }^{17}$ I. Anusiewicz and P. Skurski, Chem. Phys. Lett. 440, 41 (2007).

${ }^{18}$ G. L. Gutsev, B. K. Rao, P. Jena, X.-B. Wang, and L.-S. Wang, Chem. Phys. Lett. 312, 598 (1999).

${ }^{19}$ G. L. Gutsev, P. Jena, H.-J. Zhai, and L.-S. Wang, J. Chem. Phys. 17, 7935 (2001).

${ }^{20}$ J. Yang, X.-B. Wang, X.-P. Xing, and L.-S. Wang, J. Chem. Phys. 128, 201102 (2008).

${ }^{21}$ K. Pradhan, G. L. Gutsev, and P. Jena, J. Chem. Phys. 133, 144301 (2010).

${ }^{22}$ O. Graudejus, S. H. Elder, G. M. Lucier, C. Shen, and N. Bartlett, Inorg. Chem. 38(38), 2503 (1999).

${ }^{23}$ M. K. Scheller, R. N. Compton, and L. S. Ceederbaum, Science 270, 1160 (1995).

${ }^{24}$ R. Craciun, D. Picone, R. T. Long, S. Li, D. A. Dixon, K. A. Peterson, and K. O. Christe, Inorg. Chem. 49 (3), 1056 (2010).

${ }^{25}$ R. Cracium, R. T. Long, D. A. Dixon, and K. O. Christe, J. Phys. Chem. A 114(28), 7571 (2010).

${ }^{26}$ P. Koirala, M. Willis, B. Kiran, A. K. Kandalam, and P. Jena, J. Phys. Chem. C 114, 16018 (2010).

${ }^{27}$ M. J. Frisch, G. N. Trucks, and H. B. Schlegel et al., GAUssian 03, Revision B.04, Gaussian, Inc., Pittsburgh, PA, 2003.

${ }^{28}$ B. D. Becke, J. Chem. Phys. 98, 5648 (1993); C. Lee, W. Yang, and R. G. Parr, Phys. Rev. B 37, 785 (1988).

${ }^{29}$ M. Gerhards, O. C. Thomas, J. M. Nilles, W.-J. Zheng, and K. H. Bowen, J. Chem. Phys., 116, 10247 (2002).

${ }^{30}$ X. Li, A. Grubisic, S. T. Stokes, J. Cordes, G. F. Gantefoer, K. H. Bowen, B. Kiran, M. Willis, P. Jena, R. Burgert, and H. Schnoeckel, Science 315, 356 (2007).

${ }^{31}$ A. E. Reed, L. A. Curtiss, and F. Weinhold, Chem. Rev. 88, 899 (1988).

${ }^{32}$ S. Riedel and M. Kaupp, Coord. Chem. Rev. 253, 606 (2009).

${ }^{33}$ W. D. Knight, K. Clemenger, W. A. de Heer, W. A. Saunders, M. Y. Chou, and M. L. Cohen, Phys. Rev. Lett. 52, 2141 (1984).

${ }^{34}$ M. Götz, M. Willis, A. K. Kandalam, G. F. Ganteför, and P. Jena, Chem. Phys. Chem. 11, 853 (2010).

${ }^{35}$ M. M. Wu, H. Wang, Y. J. Ko, Q. Wang, Q. Sun, B. Kiran, A. K. Kandalam, K. H. Bowen, and P. Jena, Angew. Chem. Int. Ed. 50, 2568 (2011).

${ }^{36}$ G. L. Gutsev and A. I. Bolydrev, Chem. Phys. Lett. 108, 250 (1984).

${ }^{37}$ M. Sobczyk, A. Sawicka, and P. Skurski, Eur. J. Inorg. Chem. 3790 (2003).

${ }^{38}$ C. Sikorska, S. Freza, P. Skurski, and I. Anusiewicz, J. Phys. Chem. A. 115, 2077 (2011). 